\begin{tabular}{|ll|}
\hline $\begin{array}{l}\text { Social Work/Maatskaplike Werk Vol } 56 \text { No 3; Issue } 7 \\
\text { http://socialwork.journals.ac.za/pub }\end{array}$ & doi:http://dx.doi.org/10.15270/56-3-861 \\
\hline
\end{tabular}

THE PERCEPTIONS OF CHILDLESS WOMEN ON SURROGACY AS AN ASSISTED REPRODUCTIVE TECHNIQUE (ART) IN LEBOWAKGOMO, CAPRICORN DISTRICT, LIMPOPO PROVINCE

Maragane Jerminah Pheme, Sello Levy Sithole, Rambelani Nancy Malema

The purpose of this study was to explore the perceptions of childless women of surrogacy as an assistive reproductive technique. Childless women in marriage experience psychological problems characterised by marital instability, divorce, stigmatisation and abuse. The objectives of the study were to (a) identify childless women, (b) determine their awareness and knowledge of surrogacy, (c) establish their values and beliefs on the issue of surrogacy, and (e) assess whether they would be willing to consider surrogacy as an option to address their infertility. The study was qualitative and a case study design was used. Ten childless women were recruited from a social worker's caseload. Semi-structured interviews were conducted with these women and saturation was reached with the seventh participant. Data were analysed thematically. The findings of the study suggest that childless women knew about surrogacy as an assisted reproductive technique and that they would consider the technique as an option to address their childlessness brought about by infertility.

Ms Maragane Jerminah Pheme is an MSW student, Department of Social Work, University of Limpopo.

Prof. Sello Levy Sithole, Director, School of Social Sciences, University of Limpopo, South Africa.

Prof. Rambelani Nancy Malema, Research Manager: "Scaling-up Packages of Intervention for Cardiovascular Disease Prevention in Selected Sites in Europe and Sub-Saharan Africa" (SPICES) project, Department of Psychology, University of Limpopo, South Africa.

Maragane Jerminah Pheme, ORCID: 0000-0002-4874-9606

Sello Levy Sithole, ORCID: 0000-0001-9990-8868

Rambelani Nancy Malema, ORCIDI: 0000-0003-1036-7458

mjpheme@gmail.com

sello.sithole@ul.ac.za

nancy.malema@ul.ac.za

Keywords: assisted reproductive technique(ART), childless women, infertility, perceptions, surrogacy, South Africa 



\section{THE PERCEPTIONS OF CHILDLESS WOMEN ON SURROGACY AS AN ASSISTED REPRODUCTIVE TECHNIQUE (ART) IN LEBOWAKGOMO, CAPRICORN DISTRICT, LIMPOPO PROVINCE}

\section{Maragane Jerminah Pheme,Sello Levy Sithole, Rambelani Nancy Malema}

Ms Maragane Jerminah Pheme is an MSW student, Department of Social Work, University of Limpopo. Prof. Sello Levy Sithole, Director, School of Social Sciences, University of Limpopo, South Africa.

Prof. Rambelani Nancy Malema, Research Manager: "Scaling-up Packages of Intervention for Cardiovascular Disease Prevention in Selected Sites in Europe and Sub-Saharan Africa" (SPICES) project, Department of Psychology, University of Limpopo, South Africa.

\section{INTRODUCTION}

The purpose of the study was to explore perceptions of childless women of surrogacy as an assistive reproductive technique. Infertility, its effects and alternative options of dealing with it receive very little coverage in social work literature. A glance through the professional journal, Social Work/Maatskaplike Werk from 2003-2020 reveals no articles published on this subject (see also Poote $\&$ Van den Akker, 2009). This contribution hopes to plug this gap.

\section{STATEMENT OF THE PROBLEM}

Most (South African) women who suffer infertility experience psychological problems associated with marital instability, divorce, stigmatisation and abuse (Donkor \& Sandall 2009; Dyer, Abrahams, Mokoena, Lombard \& Spuy, 2005). Infertility deprives them of the joy of becoming a parent. Women are mostly blamed and usually carry the main burden for non-conception (Dyer et al., 2005). Infertility may result from a combination of factors related to each partner. Therefore, the goal of infertility evaluation is to identify the cause of infertility and to provide the most effective therapy (Makar \& Toth, 2002: Mashamba, 2009)

According to Vander Borght and Wyns (2018), infertility is a disease which is characterised by an inability to fall pregnant after 12 months of regular and unprotected sexual intercourse. Botes and Fourie (2019) define infertility as the inability to fall pregnant or sustain a successful pregnancy; a woman who has had miscarriages would also be regarded as infertile. About $15 \%$ to $20 \%$ of South African couples experience fertility problems (Botes \& Fourie, 2019).

Rahmani, Satterzadeb, Gholizadeh, Sheikhalipour, Allanbekhshian and Hassankhani (2011) argue that infertility has been viewed as emotionally stressful and psychologically threatening. Advances in assisted reproductive technology may offer hope to many couples experiencing infertility, whereas a few years ago this was not possible (Rahmani et al., 2011). Infertility and childlessness pose a challenge in that women may be ridiculed and excluded from social activities in the community (Van Balen \& Bos, 2009:107). Childless women often face ridicule, verbal abuse, discrimination and humiliation from family members and relatives. These women are sometimes hated to such an extent that some family members do not allow them to touch their children and they are also excluded from social events, festivals, ceremonies and birthday parties, as it is alleged that they are carriers of bad luck (Hasanpoor-Azghdy, Simbar \& Vedadhir, 2015; Mumtaz, Shahid \& Levay, 2017).

Dyer (2009) observed that regardless of the differences in sociocultural background, social consequences for infertility in different regions are similar in most cases. However, there is a difference between the experience of infertility in developed and developing countries. In developing countries the ability to conceive is central to the couples' identity, especially for women, whereas in 
developed societies voluntary childlessness is viewed as a viable and legitimate option (Daar \& Merali, 2002; Dyer, 2009; Greil, Slauson-Blevins \& McQuillan, 2010).

In this study the researchers identified childless women from a social worker's caseload to determine their awareness and knowledge of surrogacy, to establish their values and beliefs about surrogacy, and to assess whether they would consider surrogacy as a solution to their infertility.

\section{BACKGROUND LITERATURE}

Infertility affects up to $10.5 \%$ of couples of reproductive age globally (Bello, Akinajo \& Olayemi, 2014). Women's infertility is a problem that still receives little attention in South African social work literature (Poote \& Van den Akker, 2009). Work published internationally on the subject includes Remmenick's (2000) study which considered stigma and coping among childless Israeli women. Baykal, Korkmaz, Ceyhan, Goktolga and Baser (2008) also examined the opinions of infertile Turkish women on gamete donation and gestational surrogacy. The latter study concluded by acknowledging that surrogacy is increasing across the world and can be exploitative with regard to babies and commissioning parents.

A study closer home was conducted by Bello et al. (2014), who looked at in vitro fertilisation, gamete donation and surrogacy with reference to the perceptions of women attending an infertility clinic in Ibadan, Nigeria. In this study $35 \%$ of the participants were aware of surrogacy, $37.8 \%$ would accept it as treatment and most would prefer a stranger as a surrogate. Most felt that surrogates should not be paid. Acceptance of ART was associated with older age, longer duration of infertility, previous failed treatment and women without other children.

Surrogacy is explained as an arrangement whereby a woman agrees to carry a pregnancy which is achieved through assisted reproductive technology to term, and eventually hand the baby to the person or persons for whom she acts as a surrogate (Unnithan, 2013). Surrogacy therefore assumes two forms: (a) gestational surrogacy, also known as host or full surrogacy, where the embryo is the genetic material of the commissioning couple; and (b) genetic surrogacy, also known as traditional, partial or straight surrogacy, where the surrogate mother is inseminated with the commissioning male's sperm (European Union, 2013; Petitfils \& Sastre, 2014; Sharma, Kumar \& Sharma, 2013).

\section{Traditional Surrogacy}

In traditional surrogacy the surrogate (host) acts as both the egg donor and the actual surrogate for the embryo, and is impregnated using a process known as intra-uterine insemination. In this type of surrogacy the surrogate is also the biological mother of the child. This type of surrogacy is only used if the commissioning mother's egg and/or the commissioning father's sperm are not able to be used (Patel, Jadeja, Bhadarka, Patel \& Sodagar, 2018). Although this arrangement seems to be beneficial to all parties concerned, there are complex social, ethical, moral and legal issues associated with it. Such complexities have inevitably made this practice unpopular in many parts of the world.

\section{Gestational Surrogacy}

In this type of surrogacy the host's egg is not used at all. The expected child will not be related to the surrogate biologically. Using gestational surrogacy, the embryo is actually formed by using both the biological father's sperm and the biological mother's egg through a process called in vitro fertilisation (Patel et al., 2018). The right to reproduce as stated in the South African Constitution, Act 108 of 1996 of South Africa might be undermined by the factor of infertility, which might leave individuals childless.

Infertility is seen as a major medical condition that affects many married couples in Sub-Saharan Africa, and as such it attracts a wide range of interpretations (Tabong \& Adongo, 2013). Infertility is thought to be caused by several factors such as abortion, witchcraft or masturbation. Whatever the cause, the need to bear one's biological children is ubiquitous. 
Childbearing is highly valued in Ghana as in other Sub-Saharan countries such as Nigeria. In African cultures the true meanings of marriage are only fulfilled if the couple conceives and bears children. Africans consider their child to be a source of power and pride, and children act as insurance for their parents in old age (Tabong \& Adongo, 2013).

Section 12 (2) of the Constitution of South Africa (Act No 108 of 1996) allows each and every citizen the right to make decisions concerning their reproduction. This might include, inter alia, the right to perform an abortion and to opt for assisted reproduction techniques which, among other things, include surrogacy. In LGBTIQ communities surrogacy is one of the alternatives used to have children. Surrogacy is therefore viewed as of particular importance to LGBTIQ communities as it allows them to become parents with a genetic link to their offspring (European Union, 2013:30). Inevitably, surrogacy remains both a controversial topic and a costly procedure. The role of the media contributes to its negative image, as they highlight only cases where things have gone wrong. It is only recently that surrogacy has become a method adopted by LGBTIQ communities and has thus received positive media coverage (European Union, 2013; Pretorius, 1991).

Van Balen and Bos (2009) found that involuntary childlessness is regarded as a major life problem in some communities where women suffer the most because they are ridiculed and excluded from social activities (Van Balen \& Bos, 2009). Problems of involuntary childlessness faced by some women in our communities stirred the interest and curiosity of the authors to focus on surrogacy as one of the methods of assisted reproduction techniques.

\section{THEORETICAL FRAMEWORK}

Liberal Feminism (LF) was used as a lens for this study. LF is based on classic liberal thinking that individuals should be free to develop their own talents and pursue their own interests (Macionis, 2001). LF sees gestational surrogacy as a legitimate option for procreativity disadvantaged couples (Shrage, 2013). The right to enter surrogacy is part or natural extension of the right to personal autonomy as contemplated in the notion of reproductive freedom (Macionis, 2001; section 2(a) of the RSA Constitution, Act 108 of 1996). To prohibit or invalidate such contracts violates women's right to selfdetermination (Van Zyl \& Van Niekerk, 2000).

Within the gamut of surrogacy, there would always be women who want to fall pregnant but resent the challenges of child-rearing. Although motherhood from an LF perspective is an outcome of the women's liberation movement (Van Zyl \& Van Niekerk, 2000), when a woman signs a surrogacy contract, she does not only commit herself to undergo certain procedures, perform certain actions and refrain from doing others, she also commits herself to conceive, bear and give birth to another human being, and in the process form some kind of relationship with it (Van Zyl \& Van Niekerk, 2000). In this regard, surrogacy may be seen as an implicit acknowledgement that not all women who bear children need to be thought of as mothers. The process allows women who cannot bear children to assume the responsibilities of parenthood, or more specifically motherhood, which may also be realised through foster care and adoption.

Among heterosexual couples, surrogacy enables husbands and sometimes wives to have a genetic relationship with the child (Shanley, 1993). Childless women have options available of addressing the problem of infertility. They need to be educated and empowered so that they can make decisions that are appropriate for them.

\section{PURPOSE OF THE STUDY}

The purpose of this study was to explore the perceptions of childless women of surrogacy as an assistive reproductive technique.

\section{OBJECTIVES}

In this study the researchers (a) identified childless women in order (b) to determine their awareness and knowledge of surrogacy, (c) to establish the values and beliefs of these childless women on the Social Work/Maatskaplike Werk 2020:56(3) 
issue of surrogacy, and (d) to assess whether these women would consider surrogacy as a solution to their infertility.

\section{METHODS}

\section{Research design}

The researchers conducted qualitative exploratory research to gain an insight into an issue that affects childless women. Exploratory studies employ an open, flexible and inductive approach to research as they attempt to look for new insights into social phenomena (Durrheim, 2008). This design therefore dovetails with the purpose of this study, which is to explore perceptions of childless women on surrogacy as an assistive reproductive technique.

\section{Sampling}

The researchers targeted women from the ages of 35 to 45 , who did not have or never had biological children; who were either single or married; and who wanted to have children. The researchers used purposive sampling wherein the persons who satisfied the selection criteria were requested to take part in the study (De Vos, Strydom, Fouché \& Delport, 2011). Ten (10) participants were targeted. However, data saturation was reached with the seventh participant. Saturation occurs when participants repeat what has already been shared by previous participants.

\section{DATA-COLLECTION METHOD}

The researchers opted for a semi-structured one-to-one interview and were guided by questions on the interview schedule. In general, researchers used semi-structured interviews to gain a detailed picture of participants' beliefs about or perceptions of a particular topic (De Vos et al., 2011).

\section{DATA ANALYSIS}

The researchers employed thematic analysis. Six phases in the thematic analysis were followed (Clarke \& Braun, 2013).

\section{Familiarisation with data}

The researchers read and reread the data. They immersed themselves in the data by repeatedly reading through it and at the same time searching for meanings and patterns. During this process the researchers started taking notes or marking ideas for coding.

\section{Coding}

The researchers worked through the entire data set, giving full and equal attention to each data item, identifying interesting aspects of the data items that would form the basis of repeated patterns (themes). They then coded interesting features of the data in a systematic fashion across the entire data set, assembling data relevant to each code.

\section{Generating initial themes}

The researchers sorted the different codes into potential themes. In this phase they used visual representations to help sort the different codes into themes. Tables and mind maps were used to gather and arrange all data relevant to each potential theme.

\section{Reviewing themes}

The researchers reviewed and refined themes by reading all the gathered extracts for each theme to form a coherent pattern. The researchers reviewed and refined the coding until a devised thematic map was constructed. At the end of this phase the researchers had a good idea of the different themes, how they fitted together and the overall story they told about the data. 


\section{Defining and naming themes}

The researcher checked whether the themes related to the coded extracts, defined and refined the themes presented in order to analyse the data within them. For each individual theme, the researchers wrote a detailed analysis. As part of the refinement process, they identified whether or not a theme contains sub-themes.

\section{Writing up}

Writing-up entails weaving together the analytical narrative and data extracts, and contextualising the analysis in relation to existing literature.

\section{Measures to ensure trustworthiness}

\section{Credibility}

Credibility was ensured by establishing a relationship of trust with the study participants. According to De Vos et al. (2011), the goal of credibility is to demonstrate that the inquiry was conducted in such a way that the participants are accurately identified and described.

The researchers conducted individual interviews and compiled field notes. This allowed the participants an opportunity to refuse to participate in the study to ensure that those who did participate were genuinely willing to do so freely (Shenton, 2004). Checks on members were conducted whereby the data collected were verified by asking the participants to read transcripts in which they had participated (Carlson (a), 2010). An audio recorder was used. The recordings were checked to ascertain whether they had been accurately captured (Shenton, 2004).

\section{Confirmability}

Confirmability in research means the degree to which outcomes could be confirmed or corroborated by other people (Anney, 2014; Shenton, 2004). The researchers checked and rechecked the data collected during the entire research and conducted member checking by sharing transcripts with members. The researchers also engaged in reflexivity by recording thoughts, feelings, uncertainties, values, beliefs and assumptions that emerged throughout the research process in a journal (Carlson (b), 2010).

\section{Dependability}

The researchers submitted data to an external reviewer for scrutiny. One of the ways of evaluating dependability of data is inquiry audit, which means that data and relevant supporting documents (field notes, journal and transcripts) were scrutinised by an external reviewer or another researcher (Universal Teacher, 2016). According to De Vos et al. (2011), in order to enhance dependability, the researcher should ask whether the research is logical, well documented and audited. Dependability also requires the participants to evaluate the findings, interpretations and recommendations of the study to make sure that they are all supported by the data received from the participants (Anney, 2014).

\section{Transferability}

Transferability refers to the extent to which the findings of the study could be transferred to other contexts or applied to other participants (De Vos et al., 2011). The researchers provided a detailed description of the research methods used so that readers are able to make an informed judgement about whether they can transfer the findings to their own situation.

\section{FINDINGS}

Table 1 indicates the findings that were generated thematically. 
TABLE 1

AN OVERVIEW OF THEMES AND SUB-THEMES THAT WERE IDENTIFIED FROM DATA ANALYSIS

\begin{tabular}{|c|c|}
\hline Theme & Sub-theme \\
\hline \multirow[t]{3}{*}{ Theme 1: Knowledge of surrogacy } & Subtheme 1.1 : Heard about surrogacy \\
\hline & Sub-theme 1.2: Understanding of surrogacy \\
\hline & Sub-theme 1.3: Legislation on surrogacy \\
\hline $\begin{array}{l}\text { Theme 2: Cultural practices regarding children in childless } \\
\text { marriages }\end{array}$ & $\begin{array}{ll}\text { Subtheme } & \text { 2.1: Polygamy } \\
& 2.2 \text { Polygyny }\end{array}$ \\
\hline Theme 3: Religious methods of dealing with infertility & Sub-theme 3.1: Coping with infertility \\
\hline Theme 4: Social exclusion and ostracism & $\begin{array}{ll}\text { Subtheme } & \text { 4.1: Having no child to send on errands } \\
\text { Subtheme } & \text { 4.2: Feelings of inferiority } \\
\text { Subtheme } & \text { 4.3: Psychological impact of infertility }\end{array}$ \\
\hline $\begin{array}{l}\text { Theme 5: Uptake on surrogacy as an assistive reproductive } \\
\text { technique }\end{array}$ & Subtheme 5.1: Opting for surrogacy \\
\hline
\end{tabular}

\section{Theme 1: Knowledge about surrogacy}

Participants were asked if they had any knowledge about surrogacy. It became evident that they had an understanding of surrogacy, but did not know that there is legislation regarding this practice.

\section{Heard about surrogacy}

\section{The following are responses from childless women:}

I heard people talking about it on the street. People like to talk about it. (P2)

Yes, I heard about it. The doctor explained everything about it, the way it works, I heard about it in the past five years. (P3)

Yes, I heard about it. (P4)

Yes, I heard about it but I did not read about it. (P5)

Yes, I heard about it and it is a good thing. I have my uncle who did this and has children. (P6)

Findings from this study revealed that participants P2, P3, P4, P5, and P6 had heard about surrogacy from other people. Infertile couples and the people around them were more aware of the ARTs (Afshani, Abdoli, Hashempour, Baghbeheshti \& Zolfaghari, 2016). Another study in Nigeria revealed that $76.5 \%$ of infertile women heard about assistive reproductive techniques (Adesuyin, Ameh, Avidime \& Muazu, 2011).

South Africa should ensure that people are made aware of the option of surrogacy as an ART. Brochures should be made available in social workers' offices for childless couples to make informed decisions regarding the issue. The findings further confirm that a childless couple perceive surrogacy as a viable option and something highly desirable for socio-cultural reasons (Arvidsson, Vauquiline, Johnsdotter \& Essen, 2017).

\section{Sub-theme 1.1: Understanding of surrogacy}

The participants were asked what their understanding of surrogacy was. Their responses were as follows:

Because we live in a situation where people are suffering from diseases such as womb cancer, so in that case, people have difficulties in giving birth. It is a better method that will assist many women to have children because presently many women have a problem of womb and reproduction. (P6). 
Surrogacy is when one enters into an agreement to give a child on your behalf especially to those who have difficulties in giving birth. I understand it as a good thing because some people tried their best, they even went to gynaecologists but they did not get help. For them, if they really want children, surrogacy is the best method to be applied. (P5)

This happens when a married woman who has difficulties in giving birth, looks for another woman to give birth on her behalf. They take something from the man and also from me and combine them, and thereafter put them in that woman so that she can bear a child for me. They take the man's sperm and mine. (P2)

Yes, even my egg which is going to be. They take them and also put them in the womb of that woman so that she can be able to fall pregnant and thereafter give birth. (P4)

I understand that one woman keeps your egg in her ovary and gives birth for you. Mine, she keeps my egg in her ovary, be pregnant on my behalf for nine months and gives birth to my child. (P3)

According to Shaik (2015), surrogacy is a well-known method of reproduction whereby a woman agrees to become pregnant for the purpose of giving birth to a child for another woman. A study in Nigeria confirmed that among 166 women studied, only 51\% had knowledge of the assistive reproductive technique, while others had poor knowledge of this technique (Fabamwo \& Akinola, 2013). Omokanye, Olatinwo, Durowade, Biliaminu and Salaudeen (2017) also found that in Nigeria $87 \%$ of participants were aware of ART services. Among these participants, $48 \%$ were aware of surrogacy.

Rahimikian, Samani, Zandi and Mehran (2015) posit that an infertile couple's decision for a possible treatment is influenced by their knowledge and attitudes. Lack of knowledge may lead to a lack of interest in various aspects of surrogacy. Improving knowledge about surrogacy relieves future negative consequences for infertile couples, potential surrogates and children born of surrogacy (Rahimikian et al., 2015). If infertile individuals have detailed knowledge about surrogacy and its procedures, they would be able to make informed decisions regarding their infertility. Most participants in this study indicated that they possess basic knowledge of what surrogacy entails.

\section{Sub-theme 1.2: Lack of knowledge about legislation on surrogacy}

As far as applicable laws governing surrogacy were concerned, participants had this to say:

Yes, I do not know much about legislation, but what I can say is that there should be an agreement that the woman should not go away with the child. (P3)

I do not know them properly. Yes, I just know that legislation allows, but I will not be able to know which ones. (P4)

No, I have not heard nor read about the legislation or law so far. (P5)

There is no legislation or laws that I know. (P6)

I did not hear anything about legislation or laws. (P7)

All surrogacy arrangements in South Africa are legislated in Chapter 19 of the Children's Act 38 of 2005 (Nicholson \& Bauling, 2013). The participants P3, P4, P5, P6, and P7 had no knowledge of basic legislation on surrogacy in the country. Kumar (2016) found that $88.6 \%$ of the participants did not know what the legal implications of surrogacy are.

There are many ethical, social and legal issues around surrogacy and its implications (McMahon, 2013). Political regulation and medical practices vary from one country to the other (Gomez \& Unisa, 2014). Surrogacy seems to be a less talked about topic in South Africa, as there are no government awareness campaigns to educate couples and individuals affected by infertility, besides the inclusion of the procedures in the Children's Act 38 of 2005. Approximately $60 \%$ of women preferred and Social Work/Maatskaplike Werk 2020:56(3) 
supported legalised surrogacy in a study conducted in Sweden (Armuand, Lampic, Skoog-Svanberg, Wanngren \& Sydsjo, 2017). Section 9 of the Constitution of South Africa, Act 108 of 1996, states that an individual has the right to make decisions concerning reproduction. This right will only be viable when the particular individual has information regarding the rules and regulations on the various aspects of surrogacy. This will enable him or her to make an informed decision about reproductive issues. The government should take responsibility for the provision of information on surrogacy legislation where most of the people affected can access it.

\section{Theme 2: Cultural practices regarding children in childless marriages}

There are cultural practices for assisting childless couples to have children. These include polygamy if the wife is infertile, and if the infertile partner is the man, a male relative will be appointed to assist.

\section{Sub-theme 2.1: The practice of polygamy and polygyny}

Polygamy is a cultural practice that allows men to marry more than one woman (Aj, 2017; Nanda \& Warms, 2015; Olumide, 2016).

Our culture agrees with this, because in the olden days, a man used to marry a second woman for children purposes. He would make her a second wife because the first one is unable to have children, the second one should bear children for him. (P1)

They would ask a girl from the first wife's family to be married to that man so that she can have children, and the family would grow, while on the other side she would be protecting the marriage of her sister. They just married the second wife to assist her sister in giving birth. (P4)

That woman, who has difficulty in having a child, would enter into agreement with her husband to permit him to marry a second wife. (P5)

If that is the case, social worker, my younger sister would have sex with my husband so that she can give birth for us. (P6)

Polygamy is a common practice in many cultures in Sub-Saharan Africa and is used to obviate infertility and to increase the possibility of having children (Agarwali, Mulgund, Hamada \& Chyatte, 2015). Moreover, this practice is seen as the kindest solution for an infertile wife, because it is preferable to being expelled from the household and having to look for another husband (Baloyi, 2017).

Polygyny is a common form of polygamy (Topidi \& Fielder, 2016). It is a common practice around the world in more than $83 \%$ of 849 cultures. Such a practice is usually sororal, meaning men marry their wives' sisters. General and sororal polygyny were seen as practices which enable surrogate motherhood in cases where both wife and husband were infertile (Golomski, 2016). In a study conducted in Swaziland, Golomski (2016) found that a woman could make decisions to put her "own child" in the stomach of her sister, or bear a child on her sister's behalf, if her sister cannot have a child of her own. Both women would be seen as mothers of the child. Polygyny is seen to hold important implications for reproductive success (McDermott \& Cowden, 2014). Dattijo, Andreadis, Aminu, Umar and Black (2016) found that $40.4 \%$ of the respondents agreed that infertility was a valid reason for the husband to take another wife.

These findings support a study conducted by Gwandure (2013) that in some cultures, in the case of infertility, a wife would allow her husband to marry a second wife or several wives depending on the culture and economic resources in the family. Mahlobogwane (2013) also found that in African customary law, if a woman cannot give birth, the husband's family has a right to approach the wife's family to ask for a substitute. The substitute could be an unmarried sister or another female relative of the barren wife to raise a seed in his house. The position of substitute becomes an additional asset to the house of her sister; she has the rights and duties of an ordinary married wife, and children raised by her would belong to her sister's house (Mahlobogwane, 2013). 


\section{Sub-theme 2.2: Infertility among men}

In some African cultures an infertile husband's wife would be allowed to bring in her husband's brother or a relative to fulfil procreation duties. One participant (P6) made the point as follows:

My culture says that the younger brother of the husband (uncle) is the one who should have sex with his brother's wife. It is not good because to have sex with someone shows that you love him. (P6)

In this way the husband retains his masculine identity and status in his community Agarwal et al. (2015) found males to be solely responsible for $20 \%$ of infertility cases globally. Male infertility is still socially unacknowledged or a taboo protected by the wife (Rozee \& Unisa, 2016).

\section{Theme 3: Religious beliefs assist couples to cope with infertility}

The belief that children come from God appears to help couples to deal with infertility.

We know that everything is made by Him, even when women do not bear children, in my understanding, it is God who knows. Everything is known by Him, because if He has created me and even those who gossip, He will be able to give me a child; that means He has a purpose. ( $\mathrm{P} 2)$

It's is because of the Christianity that I found myself coping with the problem until today. (P7)

This correlates with a study among women seeking infertility treatment in Ghana which found that infertile women coped with their condition by drawing on their Christian faith (Tabong \& Adongo, 2013). The study further found that religion has a strong influence on acceptance of surrogacy and other ARTs (Omokanye et al., 2017). Romeiro, Caldeira, Brady, Timmins and Hall (2017) found that religious practices were associated with increased life satisfaction, and prayer was identified as one of the strategies for overcoming suffering among infertile women.

\section{Coping with infertility}

Some religious authorities think that surrogacy could be practised, while others believe that it should not be approved of, because of the many socio-cultural and legal problems associated with it (AbuRabia, 2013). In one study in Nigeria respondents believed that ART, with surrogacy as one form, contradicts religious prescripts and is an affront to God's creative power. The majority of respondents in the study believed that infertile people should wait for God's appointed time for them to have children (Arowolo \& Ayodele, 2014).

Religious practices are commonly addressed as a way for infertile couples to find meaning in life and to prevent hopelessness. According to Romeiro et al. (2017), being a religious woman and having a supportive family was associated with positive coping and finding comfort among infertile women.

In a study on religious views on surrogacy, little information emerged on factors regarding its acceptance (Aluko-Arowolo \& Ayodele, 2014). This correlates with the findings of this study from four participants (P3, P4, P5 and P7), who revealed that it is not known what their churches say about ARTs such as surrogacy.

The participants responded as follows:

Mmm, even the church; I do not have much knowledge about it. I am not sure whether it will allow or not. But I believe the church may not have problem with that method. (P3)

As far as my church, I am not sure if it allows surrogacy or not. No, I did not hear anything about it. (P4)

In my church, I have not yet heard them saying anything about surrogacy. But I will keep on asking about it. (P5)

We have never talked about it, and I also never heard them talking about it. (P7) 
The majority of childless women have no knowledge of what their church says about methods that are used to assist people who have difficulty in having children, such as surrogacy, which raises the need for further research.

Aluko-Arowolo and Ayodele's study (2014) found that the Roman Catholic Church opposes all kinds of ART because it undermines the procreative function of the marriage. ART is thus seen as dissociating the sexual act from the procreative act. Children conceived through ART are regarded as born outside of marriage. Consequently, many Christians are of the view that ART is an intrusion into the divine process of procreation (Opoku \& Addai-Mensa, 2014).

People believe in God and attend churches to find comfort, support and face various challenges in their lifetime. The pastor in the church should act as a counsellor to help infertile women to cope with their childlessness. He or she should refer them to relevant professionals with more knowledge on the matter. The infertile couple or any individual who is affected is capable of making decisions to solve the problem encountered if given the information and support available. In the liberal feminist view, interference with decisions on procreation means interference with the woman right to exercise her choices. The restrictions in the use of ART in any form would indicate unequal treatment to those who cannot conceive naturally (Aluko-Arowolo \& Ayodele, 2014).

\section{Theme 4: Social exclusion and ostracism}

Another theme that emerged during data analysis is social exclusion and ostracism. This is how it was conceptualised:

I am not feeling well because of other people's assertions. One person will tell you that, hey, do not send my child to do something for you. It affects me negatively. It does not make me feel good, because if one says, no one must send his or her child to do something for him or her while you know that you do not have children, obviously you think that they could be referring to me, since I do not have children whom to send because I am looking at his or her child. (P1)

Voluntary childlessness is not common in African countries (Oti-Boadi \& Asante, 2017). Therefore, in most communities childlessness has negative social consequences for the women affected (Abu-Rabia, 2013). Desire for children remains strong in most parts of Sub-Saharan Africa. Childlessness is considered a tragedy as children are greatly valued (Stock, 2013). In countries like Ghana, Cameroon, Egypt and Nigeria infertile women are rejected by their husbands and ostracised by society, often living as outcasts and perceived as inferior and useless (Fledderjohann, 2012; Inhorn \& Patrizio, 2015; Tabong \& Adongo, 2013). Infertile women recorded feelings of negativity expressed towards them (Rouchou, 2013).

Regardless of the causes of infertility, women get most of the blame for the reproductive setback, and suffer personal grief and frustration, social stigma and ostracism (Saoji, 2014; Tabong \& Adongo, 2013). In cases where their husbands are infertile, women shoulder the blame and remain silent (Fledderjohann, 2012; Rozee \& Unisa, 2016; Van der Geest \& Nahar, 2013). In some cultures the diagnosis of male infertility is socially unacceptable, as male infertility implies a lack of masculinity and therefore is stigmatised. This cultural tendency is presumed to protect the male ego as well as the superior role of the male in society and family (Onat, 2014). Liberal feminists cherish the ideal of an equal society that will banish gender stereotypes from among its citizens (Susser, 1995) such as the false notion that infertility is an exclusively feminine condition.

\section{Having no child to send on errands}

The responses from participants were as follows:

It affected me negatively, to an extent that when I was supposed to send my neighbours' children, their parents talked too much about me and they ended up saying I must no longer send their children, I must bear mine. (P6). 
Having no child to send on errands is a constant grim reminder of their infertility to childless women. In a study by Fledderjohann (2012) infertile women spoke of having no children to send, meaning that they have no children of their own upon whom they could rely to run errands. Having no children to send on errands has negative effects on a woman's socio-economic status. Such a woman is viewed as having no place in society (Fledderjohann, 2012). The infertile woman's financial viability is reduced, as she cannot rely on her children to generate surplus labour to be exchanged for money in the informal economy (Fledderjohann, 2012). Children, particularly in Africa, are believed to provide economic benefits that take the form of assistance that children bring to the household, such as running errands. Children serve as old age security for the parents and contribute towards the enrichment and development of a family (Atang, 2016).

The findings of this study revealed that participants P1 and P6 experience negative treatment from their social counterparts because they have no children of their own to send on errands.

\section{Feelings of inferiority}

These are some of the negative sentiments shared on this issue:

Not to have a child is too tough. When people talk about pregnancy and birth, you end up not participating because you do not know anything. They share with you and others the way they became pregnant, and the difficulties they had during pregnancy, labour pains, and you do not know anything, you end up keeping quiet as if you are not part of them. (P3)

Ferland and Caron (2013) found that the majority of infertile women felt inferior among their contemporaries. Childless women insinuated that other women implied that they (the childless women) lacked the knowledge, emotions, abilities and attributes that women acquired only upon having children, including not understanding children, parenting and being incapable of maturity and selflessness (Turnbull, Graham \& Taket, 2016). Infertility is related to feelings of inferiority and worthlessness as well as conflicts stemming from the psychological pain of infertility that can affect interpersonal relationship (Aslzaker, Pourshahbaz. Lankarani, Mohammadkhani \& Geranmayepour, 2016). In the presence of other women who had children, a response from one participant confirms what emerged in the literature as follows:

It really affects me, because when you are with other women busy talking about their children, when you are in the shops, they buy things for their children, when you are in the meeting with other women they talk about their children. You do not say anything because you do not have a child. Then it affects you negatively. (P4)

Many infertile couples endure the distress of their situation for several years. This gives rise to many psychological consequences such as relationship issues, social isolation and feelings of guilt (Malian \& Pooley, 2017). Women have negative feelings when they are in the company of other women who have children of their own.

The first reaction to the diagnosis of infertility is normally disbelief or denial. Men and women dealing with infertility issues tend to feel guilty about not fulfilling their and their partners' needs, and can suffer from mood deterioration. Experiencing negative emotions connected with the inability to be a parent is a concern to women, especially to whom motherhood is an important aspect of their social role and their individual identity (Malina \& Pooley, 2017).

The findings of this study further reveal that participants P4 and P5 experienced negative psychological feelings in the presence of other women who had children. Their responses were as follows:

Ok, to have no children in a community is a shame because they will be talking about their children did so and so and this one does not have a child. (P5)

From these comments it is evident that childless women suffer humiliation because of their condition, and feel isolated and excluded in meetings with other women who have children. Abasili (2015) 
confirms that in African cultures there is pressure on childless women to prove their womanhood by giving birth to a child. Childlessness leads to social stigmatisation (Abasili, 2015). Childless women in Sub-Saharan African countries face the most severe negative psychosocial consequences and are frequently stigmatised, isolated and neglected by the whole family, as well as the community (Hampshire \& Simpson, 2015; Ndegwa, 2016). One of the reasons why infertile women face ostracism is that the importance of children by African people has been prioritised above many other factors in a marriage (Baloyi, 2017). A woman is needed as a child bearer. Moreover, barrenness is seen as a disgrace, unacceptable and an abnormal state (Baloyi, 2017).

Most African countries are patriarchal (Muhoza, Broekhuis \& Hooimeijer, 2014) and pronatalist (Bongaarts \& Casterline, 2013). When motherhood is framed as natural, social motherhood appears as women's natural responsibility and performed out of natural love (Neyer \& Bernardi, 2011). Liberal feminists have regarded women's acquisition of control over their own reproduction not only as a necessary step to individual freedom and autonomy, but also as a fundamental condition to overcome patriarchal control and to improve the situation of women (Neyer \& Bernardi, 2011). Assistive reproductive techniques provide an alternative for the biological family in a society which has always oppressed fertile and infertile women with its demand that they reproduce (Neyer \& Bernardi, 2011).

LFs maintain that assistive reproductive techniques provide the possibility to overcome biological limitations to conceive and to reproduce. It offers the opportunity of motherhood to previously infertile women, and expands women's range of choices of voluntary and willed motherhood, which is to have as many children as they want at the time and when they would like to have them (Neyer \& Bernardi, 2011).

\section{Theme 5: Uptake on Surrogacy as an Assistive Reproductive Technique Opting for Surrogacy}

The participants in this study (P1, P3, P4, P5 and P6) considered surrogacy as an option for them to have their own children and were willing to pursue it.

The responses from participants were as follows:

Yes, I agree. It is just because I want to have a child. So that next time when other women say they are the mothers of so and so, I will also be able to say that I am the mother of so and so. (P1)

I can choose it; I can even choose it without doubts. Because I will be having my own blood child, it will be my child and my husband's, not a child from outside the family, they will not say that I am making the child to suffer, the child will be mine. (P3)

I have an interest in surrogacy. Yes, I will choose it. (P4)

Yes, I do not see that as a problem, it just needs us to have an agreement, since she will be assisting you. To get into marriage and not bear a child is tough. (P5)

Yes, (pause) I will choose since it will assist me to have my own child so that I will be able to send her or him wherever. (P6)

These findings correlate with those from a study conducted by Kian, Riazi and Bashirian (2014), which argues that $26.6 \%$ of infertile women considered surrogacy as an alternative for having children.

Hampshire and Simpson (2015) suggest that childlessness has to be regarded as a major social and public health issue in a developing country such as South Africa. For the purpose of this study, infertility can be regarded as a social issue, because it may eventually affect the psychological, social and emotional well-being of childless couples. It can also be considered a public health issue, because it affects reproductive rights. In general, more care should be exercised to achieve the holistic wellbeing of the individual (Egede, 2015). In South Africa every woman has the right to make decisions regarding reproduction. Therefore, the responsibility is upon the government to ensure that 
women facing the scourge of infertility are informed about this assistive reproductive technique in detail, so that they are able to make informed decisions.

\section{DISCUSSION}

Married infertile women should not carry the blame on their own for infertility. They should also not be viewed simply as vehicles to bear children, but rather as women who have a right to make decisions regarding their fertility.

Infertility care should be seen as a fundamental right and should not be reduced to ART alone. Other options such as family care, medical treatment and psychological support are vital. Infertility care is neglected and underestimated in developing countries. Such care includes global awareness of the problem of childlessness within the donor community, politicians and research organisations through lobbying and publishing; developing new methods to make infertility diagnoses and apply infertility treatments, including assistive reproductive techniques; simplifying in vitro fertilisation procedures; simplifying the diagnostic procedures; and reaching the general population through information, education and counselling on infertility and its consequences.

No participants in this study ever had their own children, and primary infertility is the cause of their childlessness. In most cases, advancing maternal age, which defines women between the ages of 35-40 years and above, has been found to be one of the causes of infertility.

This study explored the perceptions of childless women about surrogacy as an assistive reproductive technique. In most cultures it is unacceptable for a woman, married or single, not to have children. In this study the majority of participants had been married for more than five years, some at early an age and others at a later age. Certainly, most women in patriarchal societies expect to get married to a man with whom they would eventually have children, and for that to happen, they wait for a 'faultless' partner. Waiting for the 'perfect' partner to marry may take years; and the more years a woman waits to have children, the more years of fertility that she loses.

Findings from this study confirm that married participants were able to sustain their marriages notwithstanding their childlessness. Women may take the blame for their infertility to protect their husbands' dignity in society. In this case, it is not known whether these women are indeed infertile or they are protecting their husbands in order to save their marriages.

Most participants had heard about surrogacy from other people. The participants of this study had all obtained matric as their highest educational qualification, which attests to their literacy and access to information. Notwithstanding their educational level, none had read specifically about surrogacy, possibly because it is uncommon.

The Departments of Health and Social Development could provide information on infertility and options available on assistive reproductive techniques, as in the case of HIV/AIDS and tuberculosis. Issues of infertility are not treated as public health matters, and conditions which could be detected and treated earlier turn to serious untreatable conditions. The LFs stress that reproduction should be seen as a right for every woman. Women have to make a proper decision regarding their fertility, after having acquired relevant information about the issue.

Infertility as a factor in involuntary childlessness attracts stigmatisation to women, as they would not openly disclose their personal problems to people in the community for fear of being ostracised.

Surrogacy in some circles is so unpopular that it might be considered anathema for one woman to give birth on behalf of another. Although the participants of this study were aware of surrogacy, they were less aware of information on the legislation governing it.

Some of the participants of this study were not willing to take up surrogacy for religious reasons. They argued that their religion mediates their infertility. Although the participants revealed that they were able to cope with infertility through the support of their religion, they are still affected negatively by the Social Work/Maatskaplike Werk 2020:56(3) 
social stigma attached to childlessness. The majority of participants did not have information on what their religion says about surrogacy. They do not know how or whether their religion assists women who suffer from infertility.

The participants cited polygamy and polygyny as cultural alternatives to assisting childless women. Polygamy is accepted in various churches in South Africa such as the Zion Christian Church and the International Pentecostal Holiness Church (IPHC). In other African countries, a man is allowed to marry another woman if the first marriage is childless. Some do this without first investigating which one of them is infertile.

Infertility is both an individual and a social issue, as it brings stigmatisation and ostracism to the couple, and the woman is mostly affected. An infertile woman suffers depression, low self-esteem, inferiority and isolates herself from women who already have children, because most topics discussed among them revolve around children. Young women should be taught about reproductive health, sexually transmitted diseases and unsafe abortions as contributory factors to infertility. The government should organise awareness campaigns in clinics and hospitals on how a person can prevent infertility. In unavoidable conditions, options for assistive reproductive techniques should be made known. Surrogacy should be embraced because children born out of this procedure are genetically linked to the commissioning parents.

\section{CONCLUSION}

Surrogacy as an assistive reproductive technique was known and accepted by the majority of the study participants, who were also willing to take it up as an option. Although the women have shown an interest in surrogacy, they are not fully aware of the procedures and legislation governing the process.

Culture and religion seem to be two issues which affect decision-making regarding the uptake in ART. The participants did not know the attitudes of their religion and culture towards the issues of infertility and assistive reproduction techniques.

Polygamy and polygyny are cultural options that can address childlessness. Childless women are ostracised and excluded from social gatherings, because infertility is sometimes viewed as selfinflicted.

It is important that the government should recognise infertility as not only a medical problem, but also as a social or public health issue which contributes to psychological problems that may eventually lead to marital instability, depression, low self-esteem, inferiority complex and divorce, among others, to childless women. Communities need to be educated and made aware of infertility as a medical, psychological and social problem, and of the available options to deal with the problem.

\section{RECOMMENDATIONS}

Based on the findings of this study, the following recommendations are made:

- Infertility and childlessness should be treated as a public health issue as it can affect women psychologically;

- Public hospitals in South Africa need to focus more explicitly on assisting women who are faced with infertility;

- Further research is recommended to investigate the role of public hospitals in assisting infertile women to deal with this condition.

- Legislative requirements and services related to ART should be publicised in accessible language;

- A follow-up study focusing on the religious influence on ART uptake is recommended;

- A study on the perceptions of infertile men on surrogacy as an assisted reproductive technique (ART) is recommended. 


\section{REFERENCES}

ABASILI, A.I. 2015. Hannah's ordeal of childlessness: Interpreting1 Samuel 1 through the prism of a childless African woman in a polygynous family. Old Testament Essays, 28(3): 581-605.

ABU-RABIA, A. 2013. Infertility and surrogacy in Islamic society: Socio-cultural, psychological, ethical and religious dilemmas. The Open Psychology Journal, 6: 54-60.

ADESUYIN, A.G. AMEH, N. AVIDIME, S. \& MUAZU, A. 2011. Awareness and Perception of assisted reproductive technology practice amongst women with infertility in Northern Nigeria. Open Journal of Obstetrics and Gynaecology, 1: 144-148.

AFSHANI, S.A. ABDOLI, A.M. HASHEMPOU, M. BAGHBEHESHTI, M. \& ZOLFAGHAN, M. 2016. The attitudes of infertile couples towards assisted reproductive techniques in Yazel, Iran: A cross sectional study. International Journal of Reproductive BioMedicine, 14(12): 76-768.

AGARWAL, A. MUlGUND, A. HAMADA, A. \& CHYATTE, M.R. 2015. A unique view on male infertility around the globe. Reproductive Biology and Endocrinology, 13:37.

AJ, R. 2017. Polygamy if God wills it, it should not be a form of slavery then. Bloomington, Indiana: Xlibris.

ALUKO-AROWOLO, S.O. \& AYODELE, S.J. 2014. The effects of native culture and religious beliefs on human infertility and assisted reproductive treatment: A focus on the Ijebu people of Nigeria. African Journal of Social Sciences, 4 (4): 88-102.

ANNEY, V.N. 2014. Ensuring the quality of the findings of qualitative research: Looking at trustworthiness' criteria. Journal of Emerging Trends in Educational Research and Policy Studies 5(2): 272-281.

ARVIDSSON, A. VAUQUILINE, P. JOHNSDOTTER, S. \& ESSEN, B. 2017. Surrogate mother praiseworthy or stigmatised: A qualitative study on perceptions in Assam, India. Global Health Action. 10(1). Doi.1080/16549716.2017.1328890

ARMUAND, G. LAMPIC, C. SKOOG-SVANBERG, A. WANGGREN, K. \& SYDSJO, G. 2017. Survey shows that Swedish healthcare professionals have a positive attitude towards surrogacy but the health of the child is a concern. Acta Paediatrica, 107(1):101-109.

ASLZAKER, M. POURSHAHBAZ, A. LANKARANI, N.B. MOHAMMADKHANI, P. \& GERANMAYEPOUR, S. 2016. Effects of infertility stress, psychological symptoms and quality of life on predicting success rate of IVF/ICSI treatment of infertile women. Journal of Practice in Clinical Psychology, 4(4): 275-280.

ATANG, N.C. 2016. Involuntary childlessness: Interpretative phenomenological analysis of Black women's experiences in Luton University of Bedfordshire. Bedfordshire: Luton University of Bedfordshire (M Thesis)

BALOYI, M.E. 2017. Gendered character of barrenness in an African Context: An African pastoral study. In die Skriflig, 51(1): 1-7.

BAYKAL, B. KORKMAZ, C. CEYHAN, S.T. GOKTOLGA, U. \& BASER, I. 2008. Opinions of infertile Turkish women on gamete donation and gestational surrogacy. Fertility and Sterility, 89 (4):817-822.

BELLO, F.A. AKINAJO, O.R. \& OLAYEMI, O. 2014. In-vitro fertilisation, gamete donation and surrogacy: Perceptions of women attending an infertility clinic in Ibadan, Nigeria. African Journal of Reproductive Health, 18(2): 127-133.

BONGAARTS, J. \& CASTERLINE, J. 2013. Fertility transition: Is Sub Saharan Africa different? Population and Development Review, 38(51): 153-168.

Social Work/Maatskaplike Werk 2020:56(3) 
BOTES, A. \& FOURIE, L. 2019. Infertility and why SA should redefine disability. [Online]. Available: https//www.parent 24.co/fertility problems /infertility-and-why-sa-should-redefine disability [Accessed: 15/02/2020].

CARLSON, J.A 2010a. Avoiding traps in member checking. The Qualitative Report, 15(5): 11021113.

CARLSON, J.A. 2010b. The Qualitative Report, 15(5):1102-1113.

CHILDREN'S ACT 38 OF 2005. Government Gazette (28944). Pretoria: Government Printer.

CLARKE, V. \& BRAUN, V. 2013. Teaching thematic analysis: Overcoming challenges and developing strategies for effective learning. The Psychologist, 26 (2) 120-123. [Online].Available from: http://eprints.uwe.ac.uk/21155 [Accessed:15/02/2020].

DAAR, A.S. \& MERALI, Z., 2002. Infertility and social suffering: the case of ART in developing countries. Current Practices and Controversies in Assisted Reproduction, 15:21.

DATTIJO, L. ANDREADIS, N. AMINU. B, UMAR, N. \& BLACK, K. 2016. Knowledge of infertility among infertile women in Bauchi, Northern Nigeria. International Journal of Women's Health and Reproduction Sciences, 4(3): 103-109.

DE VOS, A.S. STRYDOM, H. FOUCHÉ, C.B.L. \& DELPORT, C.S.L. 2011. Research at grassroots for the social sciences and human service professions. $\left(4^{\text {th }} \mathrm{ed}\right)$. Pretoria: Van Schaik Publishers.

DONKOR, E.S. \& SANDALL, J. 2009. Coping strategies of women seeking infertility treatment in Southern Ghana. African Journal of Reproductive Health, 13, (4): 81 - 94.

DURRHEIM, K. 2008. Research Design. In: TERBLANCHE, M., DURRHEIM, K \& PAINTER, D. (eds). Research in Practice. Applied Methods for the Social Sciences. Cape Town. UCT Press.

DYER, S.J. 2009. Psychological and social aspects of infertility in developing countries. International Journal of Gynaecology Obstetrics, 107:25-26.

DYER, S.J. ABRAHAMS, N. MOKOENA N.E. LOMBARD, C.J. \& VAN DER SPUY, Z.M. 2005. Psychological distress among women suffering from couple infertility in S.A: A quantitative assessment. Journal of Human Reproduction, 20(7)1938-1943. doi: 10/1093/humrep/deh845

EGEDE, H. 2015. The Stigmatisation of Involuntary Childless Women in Sub-Saharan Africa: The gender empowerment and justice case for cheaper access to assisted reproductive technologies. Cardiff. Cardiff Law School. (D Thesis)

EUROPEAN UNION. 2013. A comparative study on the regime of surrogacy in EU Member States. Directorate General for Internal Policies, Policy Department C: Citizen's Rights and Constitutional Affairs. [Online] Available: http://www.europarl.europa.eu/studies [Accessed:15/12/2019].

FABAMWO, A.O. \& AKINOLA, O.I. 2013. The understanding and acceptability of assisted reproductive technology (ART) among infertile women in urban areas, Lagos, Nigeria. Journal of Obstetrics and Gynaecology, 33 (1).

FERLAND, P. \& CARON, S.L. 2013. Exploring the long-term impact of female infertility: A qualitative analysis of interviews with post-menopausal women who remained childless: Family Journal, 21, 180-188.

FLEDDERJOHANN, J.J. 2012. Zero is not good for me: Implications of infertility in Ghana. Human Reproduction, 27(5):1383-1390.

GOLOMSKI, C. 2016. Polygamy, polygyny and polyandry. Encyclopaedia of Gender and Sexuality Studies. London. The Wiley Blackwell Publishers. 
GOMEZ, V.R \& UNISA, S. 2014. Surrogacy from a reproductive rights perspective: The case of India. Journal Autrepart, 2014(2): 165-183.

GREIL, A.L. SLAUSON-BLEVINS, K. \& MCQUILLAN, J. 2010. The experience of infertility: A review of recent literature. Social Health Illness, 32(1):140-162.

GWANDURE, C. 2013. Discordant perspectives on girl fertility and egg donation in an African context. J. Hum. Ecology, 42 (3): 211-221.

HAMPSHIRE, K. \& SIMPSON, B. 2015. Assisted reproductive technologies in the third phase: Global encounters and emerging moral words. London: Berghahn Books

HASANPOOR-AZGHDY, S.B. SIMBAR, M. \& VEDADHIR, A. 2015. The social consequences of infertility among Iranian women: A qualitative study. International Journal of Fertility and Sterility, 8(4):409-420.

INHORN, M.C. \& PATRIZIO, P. 2015. Infertility around the Globe: New thinking on gender, reproductive technologies and global movements in the $21^{\text {st }}$ century. Human Reproduction Update, 21(4): 411-426.

KIAN, E.M. RIAZI, H. \& BASHIRIAN, S. 2014. Attitudes of Iranian infertile couples toward surrogacy. Journal of Human Reproductive Sciences, 7(1):47-51.

KUMAR, K.A., 2016. Awareness of legal, ethical and social aspects of surrogacy among couples attending treatment for Infertility - A questionnaire based study. Editorial Board: 4.

MACIONIS, J.J. 2001. Sociology. $\left(8^{\text {th }}\right.$ ed). New Jersey: Prentice Hall.

MAHLOBOGWANE, F.M. 2013. Surrogate motherhood arrangements in South Africa: Changing societal norms? Speculum Juris, 2: 45-58.

MAKAR, R.S. \& TOTH, T.L. 2002: The evaluation of infertility. American Journal for Clinical Pathology, 117 (1): 95-103.

MALINA, A. AND POOLEY, J.A. 2017. Psychological consequences of IVF fertilization - Review of research. Annals of Agricultural and Environmental Medicine, 24(4): 554-558.

MASHAMBA, T. 2009. Traditional healers' views on fertility: indigenous African healing practices. Indilinga: African Journal of Indigenous Knowledge Systems, 8(1):12 - 23.

MCDERMOTT, R. \& COWDEN, J. 2014. Polygyny and violence against women. Emory Law Journal, 64:1767.

MUHOZA, D.N. BROEKHUIS, A. \& HOOIMEIJER, P. 2014. Variations in desired family size and excess fertility in East Africa. International Journal of Population Research. [Online] Available: https://www.hindawi.com/journals/ijpr/2014/486079 [Accessed 8/4/2019].

MUMTAZ, Z. SHAHID, U. \& LEVAY, A. 2017. Understanding the impact of gendered roles on the experiences of infertility amongst men and women in Punjab. Reproductive Health, 2013; 10:3-3.

NANDA, S. \& WARMS, R.L. 2015. Culture counts: A concise introduction to cultural Anthropology. (4 ${ }^{\text {th }}$ ed). London: Cengage Learning Publishers.

NDEGWA, S.W. 2016. Affordable ART in Kenya: The only hope for involuntary childlessness. Facts, Views \& Vision, Issues in Obstetrics, Gynaecology and Reproductive Health, 8(2):128-13045.

NEYER, G. \& BERNARDI, L. 2011. Feminist perspectives on motherhood and reproduction.[Online].Available:https://www.su.se/polopoly_fs/1.18714.1320939635!/WP_2011_4.pd f [Accessed 8/4/2019].

NICHOLSON, C. \& BAULING, A. 2013. Surrogate motherhood agreements and their confirmation: A new challenge for practitioners? De Jure, 46(2): 510-538.

Social Work/Maatskaplike Werk 2020:56(3) 
OLUMIDE, Y.M. 2016. The vanishing black African woman: Volume II. A compendium of global skin-lightening practice. Cameroon: Langaa RPCIG

OMOKANYE, L.O. OLATINWO, A.O. DUROWADE, K.A. RAJI, S.T. BILIAMINU, S.A \& SALAUDEEN, G.A. 2017. Assisted reproductive technology: Perceptions among infertile couples in Ilorin, Nigeria. Saudi Journal for Health Sciences, 6(1):14-18.

ONAT, G. 2014. Development of a scale for determining violence against infertile women: A scale development study. Reproductive Health, 11(1):18.

OPOKU, J. \& ADDAI-MENSAH, P. 2014. A comparative analysis of in-vitro fertilization from the Christian and Islamic point of view. Global Journal of Arts Humanities and Social Sciences. 2(7):47-60.

OTI-BOADI, M. \& ASANTE, K.O. 2017. Psychological health and religious coping of Ghanaian women with infertility. Bio Psychosocial Medicine, 11(1):20.

PATEL, N.H. JADEJA, Y.D. BHADARKA, H.K. PATEL, N.H. \& SODAGAR, N.R. 2018. Insight into different aspects of surrogacy practices. Journal of Human Reproductive Science, 11 (3): 212218.

PETITFILS, C. \& SASTRE, M.T.M. 2014. French laypersons' Views on surrogate motherhood: An exploratory study. Psicológica, 35(3): 693-702.

POOTE, A.E., VAN DEN AKKER, O.B.A. 2009. British women's attitudes to surrogacy, Human Reproduction. 24 (1) 139-145. [Online] Available: https://doi.org/10.1093/humrep/den338 [Accessed: 13/12/2019].

PRETORIUS, D. 1991. Surrogate motherhood: Legal issues. Pretoria: University of South Africa (D thesis).

RAHIMIKIAN, F. SAMANI, S.O. ZANDI, A. \& MEHRAN, A. 2015. A comparative study of infertile couple's knowledge and attitudes towards surrogacy. International Journal of Fertility and Sterility, 9(1): 115-116.

RAHMANI, A. SATTERZADEB, N. GHOLIZADEH, L. SHEIKHALIPOUR, Z. ALLANBEKHSHIAN, A. \& HASSANKHANI, H. 2011.Gestational surrogacy: Viewpoint of Iranian women. Journal of Human Reproductive Sciences, 4 (3): 138-142.

REMMENICK, L. 2000. Sex roles, 43: 821-841.https://doi.org / 10.1023 /A: 1011084821700

ROMEIRO, J. CALDEIRA, S. BRADY, V. HALL J. \& TIMMINS.F. 2017. The spiritual journey of infertile couples: Discussing the opportunity for spiritual care. Religions, 8(4):76.

ROUCHOU, B. 2013. Consequences of infertility in developing countries. Perspectives in Public Health, 133(3): 174-179.

ROZEE, V. \& UNISA, S. 2016. Assisted reproduction technologies in the Global South and North: Issues, challenges and the future. New York: Routledge.

RSA Government. 1996. Constitution of the Republic of South Africa, Act No. 108 of 1996, (as amended in 1997) Government Gazette: Pretoria Big Media Publishers.

SAOJI, A.V. 2014. Primary infertility problems among female have been a source of concern in India lately. Innovative Journal of Medical and Health Science, 4(1): 332-340.

SHAIK, A. 2015. Emerging trend of surrogacy: Legal and ethical issue. Global Journal for Research Analysis, 4(10): 294-295.

SHANLEY, M.L. 1993. Surrogate mothering and women's freedom: A critique of contracts for human reproduction. Chicago Journals, 18(3) 618-639. 
SHARMA, S. KUMAR, V. \& SHARMA, R.J. 2013. Comparative review of surrogacy laws in India and abroad. International Journal of Science and Research, 4(9): 1817-1819.

SHENTON, A.K. 2004. Strategies for ensuring trust worthiness in qualitative research projects. Education for Information, 22: 63-75.

SHRAGE, L. 2013. Moral dilemma of feminism: Prostitution, adultery and abortion. New York: Routledge Publications.

SUSSER, B. 1995. Political ideology in the modern world. Boston: Allyn and Bacon.

STOCK, R. 2013. Africa South of the Sahara: A geographical interpretation. ( $\left.3^{\text {rd }} \mathrm{ed}\right)$. New York: The Guilford Press.

TABONG, P.T.N \& ADONGO, P.B. 2013. Understanding the social meaning of infertility and childbearing: A qualitative study of the perception of childbearing and childlessness in Northern Ghana. PLoS ONE, 8(1): doi:10.1371/journal.pone.0054429

TOPIDI, K. \& FIELDER, L. 2016. Religion as empowerment: Global legal perspectives. New York: Routledge.

TURNBULL, B., GRAHAM, M.L., \& TAKET, A.R. 2016. Social exclusion of Australian childless women in their reproductive years. Journal of Social Inclusion, 4(1): 102-115.

UNNITHAN, M. 2013. Thinking through surrogacy legislation in India: Reflections on relational consent and the rights of infertile women. Journal of Legal Anthropology, 1(3): 287- 313.

VAN BALEN, F. \& BOS, H.M.W. 2009. The social and cultural consequences of being childless in poor resource areas. Facts, Views and Vision, Issues in Obstetrics, Gynaecology and Reproductive Health, 1(2): 106-121.

VAN DER GEEST, S. \& NAHAR, P. 2013. Understanding life through unwanted childlessness. Ethnography and fiction for Ghana, Bangladesh and Dystopia: Anthropology Today, 29(3): 3-7.

VAN ZYL, L. \& VAN NIEKERK, A. 2000. Interpretations, perspectives and intentions in surrogate motherhood. Journal of Medical Ethics, 26(5): 404-409. 